\title{
Production of Activated Carbon from Natural Sources
}

\section{Abstract}

Activated carbon is an adsorbent in the separation and purification industries. The adsorption capacity of activated carbon depends on porosity and its surface chemistry. In this review the production of activation carbon from a large number of abundant and low-cost materials and agricultural waste such as Camellia oleifera shell, bamboo, cherry stones, waste tea, and Paulownia flower are discussed. Chemical or physical activation methods and microwave radiation methods are the commonly used techniques adopted for preparation of activated carbon.

Received: September 02, 2015; Accepted: November 27, 2015; Published: December 06, 2015

\section{Introduction}

Activated carbon, a widely used adsorbent in industrial processes, is composed of a microporous, homogenous structure with high surface area and shows radiation stability. The process for producing high-efficiency activated carbon is not completely investigated in developing countries. Furthermore, there are many problems with the regeneration of used activated carbon. Nowadays, there is a great interest in finding inexpensive and effective alternatives to the existing commercial activated carbon. Exploring effective and low-cost activated carbon may contribute to environmental sustainability and offer benefits for future commercial applications. The cost of activated carbon prepared from biomaterials is very low compared to the cost of commercial activated carbon. Activated carbon can be used in many areas as given in Figure 1.

Several reports are available in the field of production of activated carbon elsewhere. Pods of Thespesia populnea were used as a raw material for the preparation of activated carbon [1]. The prepared activated carbon was used for the adsorptive removal of Orange $G$ dye from aqueous system. Activated carbon prepared from rice husk using phosphoric acid activation has been studied by chemical activation [2]. The surface area, pore volume, and pore size distribution of carbon samples activated at 700, 800, and $900^{\circ} \mathrm{C}$ were measured. Temperature $800^{\circ} \mathrm{C}$ was found to be optimum for the increased production of pore volume especially mesopore volume. Yuso et al. synthesized activated carbon from almond shell by chemical activation with phosphoric acid [3]. The effect of activation atmosphere on property of the activated carbon produced was examined. Largitte and Lodewyckx have investigated the adsorption property of activated carbon from Bois carre' seeds for the absorption of lead recently [4].The influence of temperature on the adsorption property is examined.
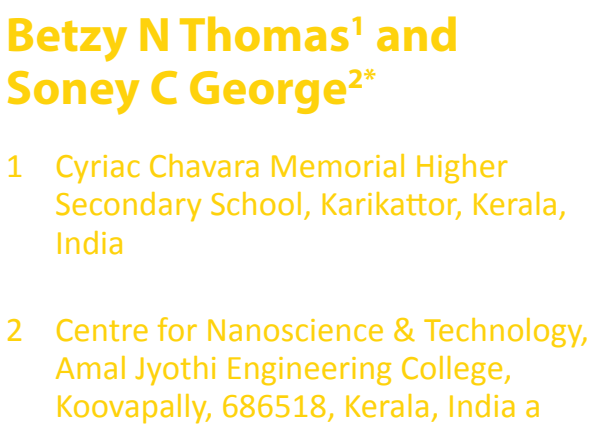

Corresponding author:

Dr. Soney C George

soneygeo@gmail.com

Professor of Chemistry, Centre for Nanoscience \& Technology, Amal Jyothi College of Engineering, Koovapally, 686518, Kerala, India.

Tel: 09447870319

Activated carbons, prepared from African biomass residue is found to be a good sorbent for removing hexavalent chromium ( $\mathrm{Cr}(\mathrm{VI}))$ from wastewater [5]. The synthesis of activated carbon from coconut husk with $\mathrm{H}_{2} \mathrm{SO}_{4}$ activation and its ability to remove textile dyes from aqueous solutions has been investigated [6]. Results show that the adsorption of both GRL and DY 12 dyes was favorable at acidic $\mathrm{pH}$. Sulaiman and co-workers synthesized the activated carbon from Palm oil fronds using physiochemical activation method, which consisted of potassium hydroxide treatment and carbon dioxide gasification [7]. The effects of variable parameters such as activation temperature, activation time and chemical impregnation on the preparation of the activated carbon and for the removal of pesticides: bentazon, carbofuran and 2, 4-Dichlorophenoxyacetic acid (2,4-D) were investigated. Angin investigated the application of activated carbon obtained from sour cherry (Prunus cerasus L.) stones for the removal of a basic textile dye, which is Yellow 18, from aqueous solutions [8]. The influence of different contact times, $\mathrm{pH}$ values and solution temperatures was investigated. Activated carbon and liquid compound fertilizer were prepared from rice husk by activation of $\mathrm{H}_{3} \mathrm{PO}_{4}$ and etching by $\mathrm{KOH}$ [9]. The resulting activated carbon exhibited excellent properties such as low ash content, large surface area, high adsorption and electrochemical performances. The waste water produced in this process was 
used to produce compound fertilizer containing $\mathrm{Si}, \mathrm{K}$ and $\mathrm{P}$. HeeChul Woo and coworkers have carried out different pretreatments (wet, oxidation and complex pretreatments) to modify activated carbon honeycomb monolith to investigate the role of surface properties of support in $\mathrm{CO}$ oxidation over $\mathrm{Pd} / \mathrm{ACHM}$ catalysts [10]. Pretreatment was an efficient way to introduce oxygen groups, especially by complex pretreatment.

Murat Erdem and co-workers have produced activated carbon from grape seed using either potassium carbonate $\left(\mathrm{K}_{2} \mathrm{CO}_{3}\right)$ or potassium hydroxide $(\mathrm{KOH})$ [11]. The carbonization experiments were accomplished at 600 and $800^{\circ} \mathrm{C}$. The effects of the experimental conditions on the yields and properties of these activated carbons were analyzed under identical conditions. An increase in temperature at same concentrations for both $\mathrm{K}_{2} \mathrm{CO}_{3}$ and $\mathrm{KOH}$ led to a decrease in yields of activated carbons. The lowest activated carbon yields were obtained at $800^{\circ} \mathrm{C}$ at the highest reagent concentration (100 wt\%) for both $\mathrm{K}_{2} \mathrm{CO}_{3}$ and $\mathrm{KOH}$. The obtained activated carbons were mainly microporous. Low-cost activated carbon from the sour cherry (Prunus cerasus L.) stones was prepared by chemical activation using zinc chloride [12]. The effects of the activation temperature and the impregnation ratio on the surface and chemical properties of activated carbon were investigated.

The aim of this review is to narrate the preparation of activated carbon from various natural sources with reference to the origin of the source, method of preparation and the potential application. A general method of preparation of activated carbon from natural sources is given in Figure $\mathbf{2}$.

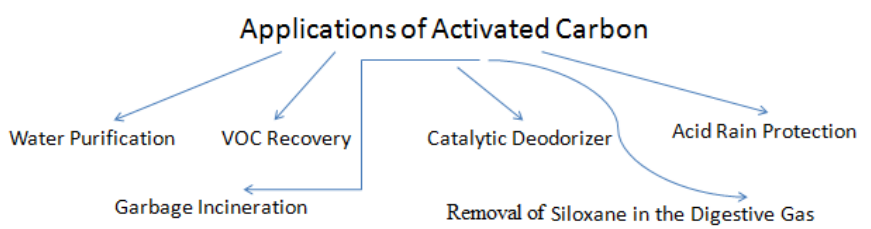

Figure 1 General Applications of activated carbon.

\section{Preparation of Activated Carbon from Camellia Oleifera Shell}

Camellia oleifera is an edible oil woody species, found in southern provinces of China. The shells of nuts are agricultural waste and are usually discarded or burnt. The shell of Camellia oleifera nuts consists of cellulose, hemi-cellulose, and lignin. Activated carbon based on shell of Camellia oleifera was prepared by Kang et al. [13]. Initially, C. oleifera shell was washed with water and dried in an oven and crushed and sieved. It was carbonized at $450^{\circ} \mathrm{C}$ in a revolving furnace in the activation pressure using water vapor at different temperatures. The resulting activated carbon was impregnated with phosphoric acid and then dried to remove water. The dried samples were pyrolyzed under different temperatures to modify their porous structures. By this process highly developed mesoporous activated carbon was prepared. The activated carbon produced exhibits high adsorption capacity with iodine value at $1326 \mathrm{mg} / \mathrm{g}$, methylene blue value $330 \mathrm{mg} / \mathrm{g}$, total pore volume $1.17 \mathrm{~m}^{3} / \mathrm{g}$, and BET surface area $1608 \mathrm{~m}^{2} / \mathrm{g}$.

\section{Preparation of Activated Carbon from Bamboo Chips}

Recently Bamboo chips were used as raw materials to prepare activated Carbons (BbAC) [14]. Initially dried bamboo waste was crushed to the mesh size of 1-2 mm. It was treated with $\mathrm{H}_{3} \mathrm{PO}_{4}$ and $\mathrm{K}_{2} \mathrm{CO}_{3}$ at different impregnation ratio at room temperature. The mixture was heated to $700-850^{\circ} \mathrm{C}$ after dehydration. It was found that surface area and pore volume of BbAC increased with increasing impregnation ratio and reached maxima at the impregnation ratio of $3: 1$ at $750^{\circ} \mathrm{C}$. Maximum SSA of $2237 \mathrm{~m}^{2} / \mathrm{g}$ and a maximum total pore volume of $1.23 \mathrm{~cm}^{3} / \mathrm{g}$ with the micro pore ratio of more than $90 \%$ was obtained.

\section{Preparation of Aactivated Carbon from Cherry Stones}

Kernels of cherry stones were used for producing activated carbon by Pietrzak and co-workers [15]. It was crushed and pyrolysed. Both physical activation and chemical activation methods were used to activate the carbon produced. A stream of carbon dioxide followed by $\mathrm{KOH}$ was used here. Activated carbons with a surface

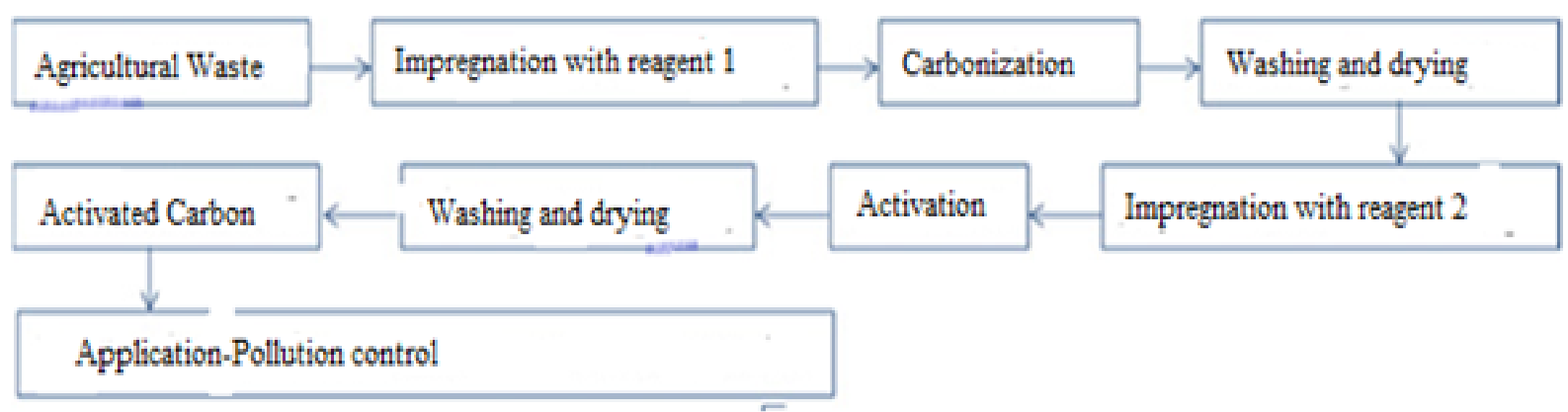

Figure 2 A general method of preparation of activated carbon from natural source. 
area ranging from 361 to $1173 \mathrm{~m}^{2} / \mathrm{g}$ and pore volume from 0.21 to $0.74 \mathrm{~cm}^{3} / \mathrm{g}$ obtained. It was found that the property depends up on the pyrolysis conditions and activation procedure adopted. Moreover, the activated carbons thus produced were tested for adsorption of $\mathrm{NO}_{2}$ and $\mathrm{H}_{2} \mathrm{~S}$ from a gas steam as well as for removal of methylene blue and iodine from the liquid phase.

\section{Preparation of Activated Carbon from Foxnut (Euryale Ferox) Shell}

Kumar and Jena found that Fox nutshell is a conducive raw material for preparing activated carbon due to its low ash (5\%) and high volatile matter (70.1\%) [16]. It is a tropical plant belongs to the family of waterlily (Nymphaeaceae). In the procedure for preparing activated carbon, the Foxnutshell was dried and crushed initally and sieved to collect particles of size ranges from 1.4-2.0 $\mathrm{mm}$. It was heated and carbonized after impregnated with $\mathrm{ZnCl}_{2}$ solution. The BET surface area, the microporous surface area, total pore volume, and micropore volume have been obtained as $2869 \mathrm{~m}^{2} / \mathrm{g}, 2124 \mathrm{~m}^{2} / \mathrm{g}, 1.96 \mathrm{~cm}^{3} / \mathrm{g}$, and 1.68 $\mathrm{cm}^{3} / \mathrm{g}$, respectively, and the microporosity percentage of the prepared activated carbon is $85.71 \%$.

\section{Preparation of Activated Carbon from Holm Oak (Quercus llex) Acorns}

Oduncu et al. used Holm Oak acorns as a raw material for preparing activated carbon [17]. Holm Oak (Quercus ilex) is an evergreen broadleaf tree found in humid Mediterranean regions and contains high levels of carbon material. Carbonization is carried out in $\mathrm{CO}_{2}$ or steam atmosphere and later it is activated with various activating agents such as $\mathrm{KOH}, \mathrm{ZnCl}_{2}, \mathrm{H}_{3} \mathrm{PO}_{4}$, and $\mathrm{H}_{2} \mathrm{SO}_{4}$. The impregnated material is carbonized below $800^{\circ} \mathrm{C}$. It was found that the samples generated using $\mathrm{ZnCl}_{2}$ as an activating agent results in better texture properties and adsorption, with a dye removal efficiency of $93.5 \%$.

\section{Preparation of Activated Carbon from Paulownia Flower}

Chang and coworkers used paulownia flower (PF) of Paulownia tomentosa as a precursor for the preparation of activated carbons by high temperature carbonization and alkali activation [18].

In the carbonization procedure, mature PF was collected and it was subjected to pyrolysis. Subsequently, the PFC was mixed with $\mathrm{KOH}$ at $\mathrm{KOH}$ : PFC mass ratio of 2, 3, or 4 . The mixture was further pyrolyzed at $800^{\circ} \mathrm{C}$ for $1 \mathrm{~h}$ in nitrogen atmosphere to create pores. The enhanced specific surface areas, versatile pore texture with the coexistence of bothmicropores and meso-/macropores, apparently increased hydrophilicity and moderate graphitization made PF based activated carbons high performance electrode materials of supercapacitors.

\section{Preparation of Activated Carbon from Flower from Pineapple Waste Biomass for Dye Removal}

Solid pineapple waste biomass (SPWB) was utilized to produce activated carbon by Zakaria et al. [19]. Washed and dried sample was treated with $\mathrm{ZnCl}_{2}$ with a ratio of $1: 1$ and then dried at $110^{\circ} \mathrm{C}$, followed by carbonization at $500^{\circ} \mathrm{C}$ in order to obtain a high adsorbent carbon. It can be concluded that adsorbent prepared using a 1:1 ratio has the highest dye removal capacity due to its high surface area $\left(914.67 \mathrm{~m}^{2} / \mathrm{g}\right)$ and adsorption capacity at 288.34 $\mathrm{mg} / \mathrm{g}$. Thus, this study demonstrated the potential of using pineapple waste biomass as cheap and efficient raw materials to produce activated carbon for dye removal from wastewaters.

\section{Preparation of Activated Carbon from Sludge and Sugarcane Bagasse for Removing Lead Ion from Wastewater}

Sugar cane bagasse is a challenge for treatment and disposal [20]. Bagasse could serve as an additive for the production of sludgebased adsorbents to enhance its adsorption capacity. The bagasse after extracting sugarcane juice by crushing and squeezing was collected and dried along with sludge at $105^{\circ} \mathrm{C}$. They were grounded and sieved to different particle. The adsorbent is activated by $\mathrm{KOH}$ through pyrolysis and modified with $\mathrm{HNO}_{3}$ to remove lead from the contaminated water.

\section{Preparation of Activated Carbon from Waste Tea}

Waste tea (WT) was crushed and sieved to get samples of particle size $500 \mathrm{~mm}$ size were used to prepare activated carbon. Both $\mathrm{H}_{3} \mathrm{PO}_{4}$ solution and anhydrous $\mathrm{K}_{2} \mathrm{CO}_{3}$ (Sigma Aldrich) were used as chemical activating agents in this study. Activation with $\mathrm{K}_{2} \mathrm{CO}_{3}$ required a high temperature $\left(800^{\circ} \mathrm{C}\right)$ for the heating process, however, the temperature was lower $\left(450^{\circ} \mathrm{C}\right)$ for activation in the presence of $\mathrm{H}_{3} \mathrm{PO}_{4}$. Activated carbon produced is used as electrode material for superapcitors.

The comparison of properties and the main application of activated carbon produced from different sources are displayed in Table 1. Activated carbon produced from Foxnut (Euryale ferox) shell exhibits highest BET surface area and total pore volume among the activated carbon produced from different sources. Activated carbon from all the sources is useful as adsorbent in different respects.

\section{Conclusion}

Preparation of activated carbon from different sources is discussed in this review. Several low cost natural materials are available in an around the world to produce activated carbon. Here the preparation of activated carbon from natural sources such as Camellia oleifera shell, bamboo waste, cherry stones, waste tea, and Paulownia flower are discussed. Chemical activation methods are commonly used to prepare the activated carbon in most cases. The activating agents used mainly are $\mathrm{ZnCl}_{2}, \mathrm{~K}_{2} \mathrm{CO}_{3}, \mathrm{NaOH}$ and $\mathrm{H}_{3} \mathrm{PO}_{4}$. Activated carbon produced from Foxnut (Euryale ferox) shell exhibits highest BET surface area and total pore volume among the activated carbon produced from different sources. Activated carbon produced from different sources is good in removing hazardous compounds and dyes from industrial waste gases and wastewater in addition to their application as electrode material in super capacitors. 
Table 1 Performance of Activated Carbon.

*Acid-bagasse-sludge-based adsorbent-KOH (Acid-B-SBA-K).

\begin{tabular}{|c|c|c|c|c|c|}
\hline Source & Activating agent & $\begin{array}{c}\text { Carbonization } \\
\text { temperature } \\
\left({ }^{\circ} \mathrm{C}\right)\end{array}$ & $\begin{array}{l}\text { Surface area } \\
\text { (BET) } \mathrm{m}^{2} / \mathrm{g}\end{array}$ & $\begin{array}{c}\text { Total Pore } \\
\text { volume } \mathrm{cm}^{3} / \mathrm{g}\end{array}$ & Applications/uses \\
\hline Camellia Oleifera Shell ${ }^{13}$ & $\mathrm{H}_{3} \mathrm{PO}_{4}$ & 450 & 1608 & 1.17 & $\begin{array}{l}\text { For the adsorption of methylene blue and } \\
\text { iodine }\end{array}$ \\
\hline Bamboo chips ${ }^{14}$ & $\mathrm{H}_{3} \mathrm{PO}_{4} \& \mathrm{~K}_{2} \mathrm{CO}_{3}$ & $700-850$ & 2237 & 1.23 & As an adsorbent for ciprofloxacin. \\
\hline Kernels of Cherry Stones ${ }^{15}$ & $\begin{array}{l}\text { Stream of } \mathrm{CO}_{2} \text { and } \\
\mathrm{KOH}\end{array}$ & $500 \& 800$ & 361 to 1173 & 0.21 to 0.74 & $\begin{array}{l}\text { Adsorption of } \mathrm{NO}_{2} \text { and } \mathrm{H}_{2} \mathrm{~S} \text { from a gas } \\
\text { steam as well as for removal of methylene } \\
\text { blue and iodine from the liquid phase. }\end{array}$ \\
\hline Foxnut (Euryale ferox) shell ${ }^{16}$ & $\mathrm{ZnCl}$ solution. & $500-700$ & 2869 & 1.96 & $\begin{array}{l}\text { Removing hazardous compounds from } \\
\text { industrial waste gases and wastewater. }\end{array}$ \\
\hline Holm Oak ${ }^{17}$ & $\begin{array}{c}\mathrm{KOH}, \mathrm{ZnCl}_{2^{\prime}}, \mathrm{H}_{3} \mathrm{PO}_{4^{\prime}} \\
\mathrm{H}_{2} \mathrm{SO}_{4}\end{array}$ & 750 & 1305 & 0.621 & Removal of dye \\
\hline Paulownia flower (PF) ${ }^{18}$ & $\mathrm{KOH}$ & 800 & 1471 & & $\begin{array}{l}\text { High performance electrode materials of } \\
\text { supercapacitors. }\end{array}$ \\
\hline $\begin{array}{l}\text { Solid pineapple waste biomass } \\
\text { (SPWB }{ }^{19}\end{array}$ & $\mathrm{ZnCl}_{2}$ solution & 500 & 914.67 & 0.56 & Removal of Dye from waste water \\
\hline $\begin{array}{l}\text { Sugar Cane Bagasse } 20 \\
\text { (B-SBA-K)* }\end{array}$ & $\mathrm{KOH}$ with $\mathrm{HNO}_{3}$ & 800 & 806 & 0.678 & $\begin{array}{l}\text { Low-cost adsorbent for heavy metals with } \\
\text { great adsorption capacity. }\end{array}$ \\
\hline Waste tea ${ }^{21}$ & $\mathrm{H}_{3} \mathrm{PO} 4 / \mathrm{K}_{2} \mathrm{CO}_{3}$. & $450 / 800$ & $1327 / 1125$ & $0.865 / 0.050$ & As electrode materials in supercapacitors \\
\hline
\end{tabular}




\section{References}

1 Arulkumar M, Sathishkumar P, Palvannan T (2011) Journal of Hazardous Materials 186: 827-834.

2 Somasundaram SK, Sekar Gupta VK, Ganesan S (2013) Journal of Molecular Liquids 177: 416-425

3 De Yuso AM, Rubio B, Izquierdo MT (2014) Fuel Processing Technology 119: 74-80.

4 Largitte L, Lodewyckx QP (2014) Journal of Environmental Chemical Engineering Journal of Environmental Chemical Engineering.

5 Gueye M, Richardson Y, Kafack FT, Joel Blin (2014) Journal of Environmental Chemical Engineering 2: 273-281.

6 Aljeboree AM, Alshirifi AN, Alkaim AF (2014) Arabian Journal of Chemistry 7: 101-108.

7 Danish M, Hashim R, Mohamad Ibrahim MN, Sulaiman O (2014) Biomass and Bioenergy 61: 167-178.

Angin D (2014) Bioresource Technology 168: 259-266.

9 Li Wang, Zhang Y, Yang Lou, Yanglong Guo, Guanzhong Lu, et al. (2014) Fuel Processing Technology 122: 23-29.

10 Ho PH, So-Yun Lee, Lee D, Hee-Chul Woo (2014) International journal of hydrogen energy 1-9.
11 Okman I, Karagöz S, Tay T, Erdem M (2014) Applied Surface Science 293: $138-142$.

12 Kang S, Jian-chun J, Dan-dan C (2011) Biomass and Bioenergy 35 3643-3647.

13 Wang YX, Ngo HH, Guo WS (2015) Science of the Total Environment 533: 32-39.

14 Nowicki P, Kazmierczak J, Pietrzak R (2015) Powder Technology 269: 312-319.

15 Kumar A, Jena HM (2015) Applied Surface Science 356: 753-761.

16 Un UT, Ates F, Erginel N, Ozcan O, Oduncu E (2015) Journal of Environmental Management 155: 89-96.

17 Chang J, Gao Z, Wang X, Wu D, Xu F, et al. (2015) Electrochimica Acta 157: $290-298$

18 Mahamad MN, Zaini MAA, Zakaria ZA (2015) International Biodeterioration \& Biodegradation 102: 274-280.

19 Hu-Chun T, Zhang H, Jin-Bo Li , Ding W (2015) Bioresource Technology 192: 611-617.

20 Inal IIG , Holmes SM, Banford A, Aktas Z (2015) Applied Surface Science 357: 696-703. 